\title{
USE OF ICT TOOLS IN HYBRID ENVIRONMENTS OF FACE-TO- FACE AND VIRTUAL LEARNING. EXPERIENCE IN TWO MECHANICAL ENGINEERING SUBJECTS OF MASTER'S DEGREE
}

\author{
A.M. Pedrosa, M.P. Vila, C. Llopis-Albert, M.J. Rupérez \\ Universitat Politècnica de València (SPAIN)
}

\begin{abstract}
In March 2020, the World Health Organization (WHO) raised to an international pandemic level the outbreak of the coronavirus (COVID-19) disease caused by the Severe Acute Respiratory Syndrome Coronavirus 2 (SARS-CoV2). Consequently, the Spanish government declared the State of Alarm on March 14th, 2020. From that moment on, all non-essential activities were tightened lockdown. This measure affected all levels of education, and face-to-face learning was suspended until the end of the academic year.
\end{abstract}

While the last year all the educational community was forced to suddenly move to online platforms, this year has been rather marked by the need of flexibility in the learning model. The main reasons are the constant threat of global lockdowns, the changing local mobility restriction measures and the forced isolation or quarantine in case of infections or close contact with someone with a positive Polymerase Chain Reaction (PCR) test. This situation has drastically affected the face-to-face teaching model. At the same time, this uncertain scenario has undoubtedly been an opportunity to implement Information and Communications Technology (ICT)activities in our teaching.

This paper presents some actions implemented in two subjects of mechanical design of two different master's degrees with 36 and 19 students, respectively. The developed resources concern to the learning materials provided to the students, both for theoretical and practical lessons. The audio-visual materials generated over the classes, both videos and annotations on the virtual whiteboard, has also been managed. Finally, the delivery and defence of the students' works have been adapted. As it was foreseeable all, some of the students or the teacher, have followed the classes online over the term. In all cases, the developed materials and the methodology followed have been valid for use in face-to-face teaching, online and blended learning, thus providing the flexibility required.

The level of success has been measured, mainly through a survey answered by the students. In addition, it has been analysed objective data, such as the marks and the number of visits or downloads of the documents uploaded to the UPV e-learning platform. Finally, it is concluded which actions taken would be valid for the post-COVID era.

Keywords: Information and Communications Technology, e-Learning, blended Learning, COVID19, methodology, evaluation.

\section{INTRODUCTION}

The adoption of Blended Learning (BL), a combination of traditional face-to-face and technologymediated teaching, was increasing before global pandemic in higher education around the world. In fact, some experts pointed out that BL would become the "new traditional model" [1] or the "new normal model" in the offer of higher education courses [2]. However, the study of the implementation of this model highlighted the existing limitations in higher education, due in part to disagreement on how institutions define and measure BL [3].

$B L$ began in many places as an initiative embraced by individual teachers interested in using both online and traditional strategies to improve student learning outcomes, rather than being promoted as a strategic institutional initiative [4]. Graham et al. noted in 2012 that many higher education institutions in the awareness/exploration stage wanted to transition to early adoption/implementation, and recommended future research on this transition [5]. However, the sudden outbreak of the global pandemic by COVID-19 forced an immediate adaptation of the traditional face-to-face educational model to an on-line model mediated by technology to the end of the 2019-2020 academic year. 
During the 2020-2021 academic year, due to the relaxation of some restriction measures, the higher educational institutions resort to the $B \mathrm{~L}$ models. Different $\mathrm{BL}$ models have been implemented by individual teachers because there has not been time to develop an institutional agreement or strategy on how to implement them. The teachers, based on the knowledge acquired when developing the online learning model to finish the 2019-2020 academic year, have implemented their own initiatives to obtain the best student learning outcomes; each one with the tools at their disposal, both technological and institutional, has developed a different $\mathrm{BL}$ model for each subject. Now, it is the time to check the results to extract some conclusions about how to implement an institutional BL model.

In this context, Information and Communication Technologies, ICTs, has taken on special relevance since they have supported the learning and evaluation processes in both models online and BL.

The actions carried out are framed in an institutional project of the Universitat Politècnica de València (UPV).

\section{METHODOLOGY}

The methodology involves two subjects of mechanical design detailed in the Table 1.

Table 1. Details of the subjects.

\begin{tabular}{l|c}
\hline \multicolumn{1}{c|}{ Subject and year } & Total number of students in the subject \\
\hline $\begin{array}{l}\text { Technology of Machines for levelling (TML) } \\
1^{\text {st }} \text { Year Master's Degree }\end{array}$ & 36 \\
\hline $\begin{array}{l}\text { Materials Behaviour in Service (MBS) } \\
1^{\text {st }} \text { Year Master's Degree }\end{array}$ & 19 \\
\hline \hline
\end{tabular}

The developed resources concern to the learning materials provided to the students, both for theoretical and practical lessons. The following sections describe, firstly, the actions carried out in the theoretical classes, then the modifications referred to the lab sessions and finally how the defense and evaluation of students' works has been carried out.

In all cases, the institutional platform provided by the UPV has been used. The platform is available only to members of the course, it allows to provide students the learning materials, send announcements and organize tasks, among other features. The classes had broadcast through Teams ${ }^{\circledR}[6]$ in both cases, when they were in the university classroom, but also when they were completely on-line.

\subsection{Theoretical classes}

The theoretical classes followed the usual schedule. All the classes were broadcast live for those students that could not attend the session. Additionally, all the sessions were recorded by Teams $®$ which keeps the recordings in the corresponding "Team" of the subject. Having these recordings available has undoubtedly been a great advantage for students, most of them have acknowledged consulting the recordings regardless of whether they attended class or they did not.

To visualize the record of a session, the student can easily find it in the meeting generated for the class, but the only information of the contents of the records is the date of the session which could be a drawback when the student needs to consult a specific theoretical explanation or the resolution of a problem. For this reason, to facilitate the access to the contents, for each topic of the subject a document was created with the date of each session, accompanied by a brief description of the contents of the session and a link to the video. 
Subject: MATERIALS BEHAVIOR IN SERVICE

Theoretical videos recorded in Teams.

Topic 1. Introduction

Day 09/24:

Cast iron / steel. Plane stress. Mohr's circle

https://media.upv.es/plaver/?id=ea35d880-fe69-11ea-b0c4-c7b2d7fc79f7

Day 01/10:

End of topic 1. Mechanical behavior of materials. Types of failure

https://media.upv.es/plaver/?id=f79ea4b0-03e7-11eb-a0bb-f5f73c245483

Free-Body Diagrams. Distribution of stress. Question C01

https://media.upv.es/player/?id=f916a940-03e8-11eb-a0bb-f5f73c245483

Figure 1. Example of the organization of the recordings of the sessions of a subject.

The classroom blackboard has been replaced by an electronic whiteboard. To speed up the resolution of questions and problems, for each problem a template was prepared with the data and images of the statement as well as the mathematical expressions necessary for each section. Figure 2 shows an example of a transmission shaft calculation problem.
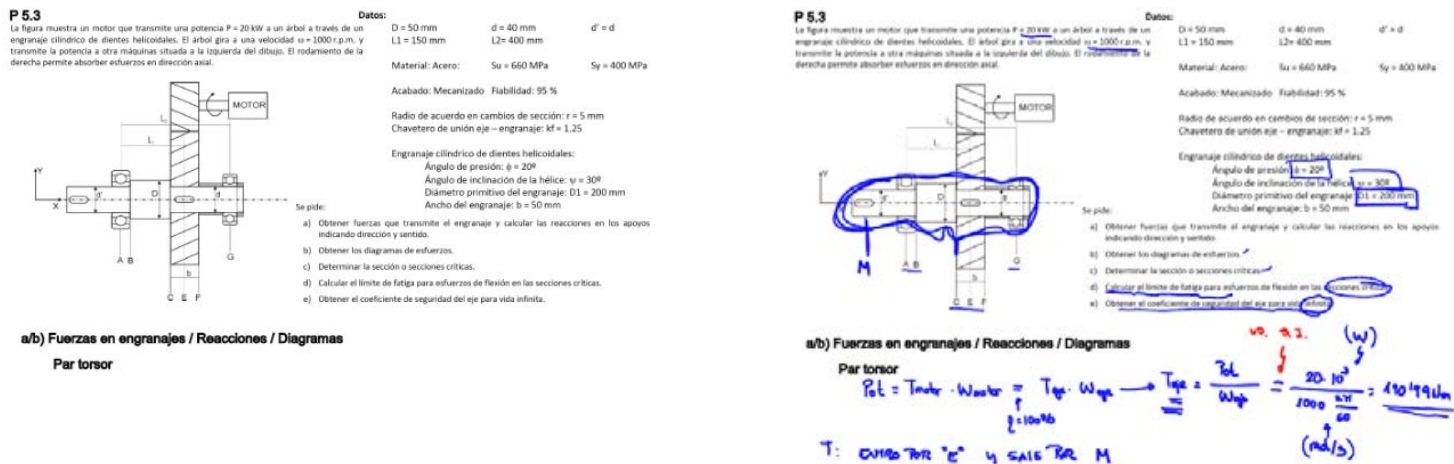

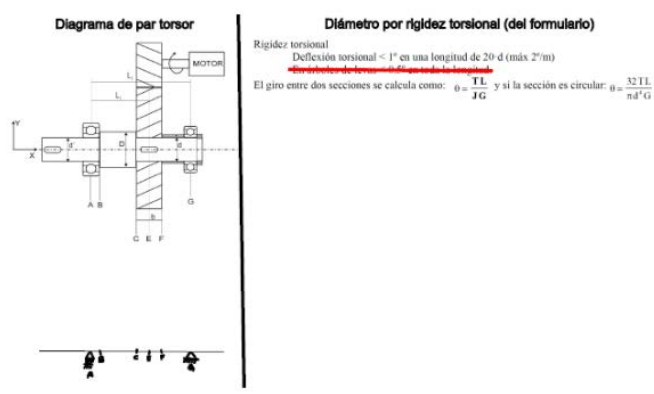

(a)

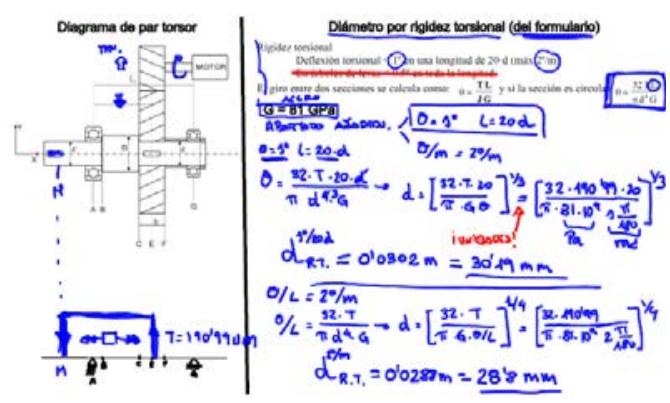

(b)

Figure 2. Problem solved in the electronic whiteboard: (a) template (b) detailed resolution.

All the pdf files created during the classes with the electronic blackboard, were properly sorted and identified. The students could consult all of them in the platform of the subject.

\subsection{Lab sessions}

Referring to the lab sessions, the most important limitations have been the reduction in the capacity of the laboratories due to the pandemic and the uncertainty arising from potential confinements. Despite 
these conditions, most of them could adapted to BL. The most remarkable actions carried out are described below.

\subsubsection{Computer lab sessions}

In the computer lab the students learn to model and solve a mechanical problem with a Finite Element software. During the sessions before the pandemic, the teacher first gave a general explanation and then the students used to work in pairs following the required steps detailed in the booklet. When it was necessary, the students could consult the teacher to solve their doubts. Considering that, this year, the lab sessions were to be taught online and the students had to work autonomously, the booklets have been revised, improving the explanations where the experience showed that the students required more help from the teacher to understand.

In addition, a novelty related to ICT has been the insertion of links in the booklet of small videos in which the execution of the commands described in the text could be visualized, thus facilitating the location of some menus of the software.

The delivery of the results of the lab session consisted of uploading files generated with the program and answered some questions, related to the steps followed in the model, the mastery of the software and to the theoretical contents of the subject. The task included an editable pdf file where the students must insert their answers. To better organize the fulfilment of the task, for each required action a warning was inserted in the booklet. Figure 3 shows a warning and the corresponding question.

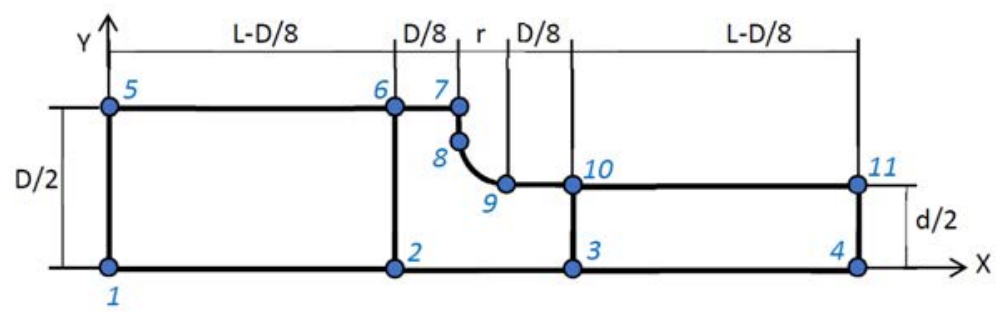

Figure 1. Keypoints, lines and areas to generate the volume.

Calculate the coordinates of the keypoints from the input data provided by the teacher and complete the table question 1 of the task.

(a)

1. Insert the data of your model:

Intput data

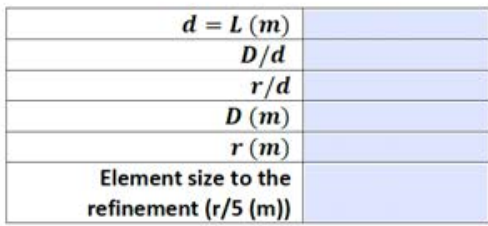

Coordinates of the keypoints $(\mathrm{m})$

\begin{tabular}{|l|l|l|l|l|l|l|l|l|l|l|l|}
\hline & $K p 1$ & $K p 2$ & $K p 3$ & $K p 4$ & $K p 5$ & $K p 6$ & $K p 7$ & $K p 8$ & $K p 9$ & $K p 10$ & $K p 11$ \\
\hline $\mathrm{X}$ & & & & & & & & & & & \\
\hline $\mathrm{Y}$ & & & & & & & & & & & \\
\hline
\end{tabular}

(b)

Figure 3. Example of a question of a task: (a) warning in the booklet (b) exercise in the task.

The UPV platform allows to programme the tasks and organize de deliveries for each group.

\subsubsection{Laboratory sessions}

The drop of the capacity of the laboratories has mostly affected the laboratory sessions, for that reason, one of the two laboratory sessions have been moved to computer lab sessions. The objective of the lab session was to determine the cause of the failure of a mechanical part. After a theoretical general introduction through Teams $®$ the students had to work on several components during the session. The 
work could be done in groups of a maximum of three students. The students could use Teams $₫$ or another platform to meet. During the session, the students could contact the teacher to consult their doubts.

For each component to analyse, the students had a booklet with a description of the machine to which the part belonged and the working conditions of the machine when the failure was produced. In the booklets were also included links to web pages with additional information that could be useful to describe the failure. Figure 4 shows some examples.

\section{Exchanger tube of a thermal power plant}

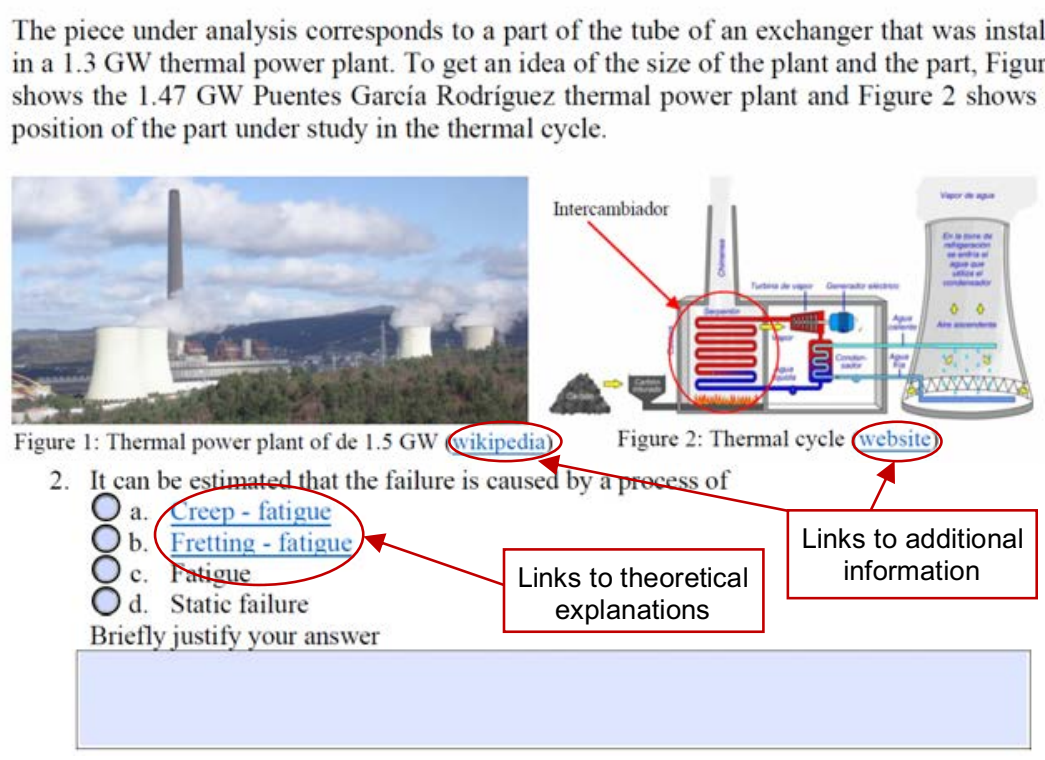

Figure 4. Example of links to web pages with additional information.

The students also had a complete photographic report of the pieces under study. In this case, also the UPV platform was used to programme the tasks and organize de deliveries.

\subsection{Students' work}

In the subject Materials Behaviour in Service the students made a work. The work had three deliveries over the year programmed according to the theoretical lessons. In the last session of the course, the students had to present their work. The work could be done in groups of a maximum of two students.

The students were aimed to record a video presenting their work instead of doing a live presentation. This activity not only contributed to the use of several ICT tools by the students but also allowed the students to be aware during the presentation of their colleagues.

The students also did a co-evaluation of the works. The platform used was, in this case, google forms. After watching the video of each work, the teacher did the corresponding comments and then the students did the evaluation. For that issue, the form had three different parts, first a rubric with four levels to evaluate some aspects of the work: the rigor of the justification, the mastery on the numerical tool employed or the adequacy of the conclusions (in Figure 5), among others. In the second part the students had to mark their colleagues and finally they could write a global commentary of the work. After watching and evaluating all the presentations, the students voted for the top three works which received extra points in the evaluation. 
Conclusiones

227 respuestas

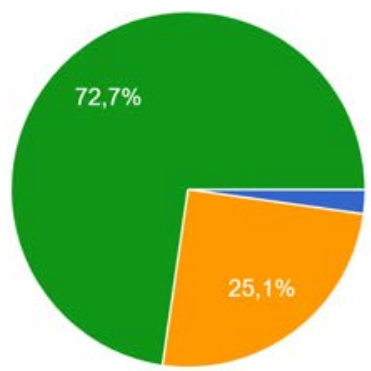

Ausencia de conclusiones o incoherentes

Falta de rigor o no tiene nada que ver con los objetivos

Relacionadas con los objetivos del trabajo, pero los argumentos son simples

Queda muy clara la relación con los objetivos. Los argumentos son sólidos. Relaciona con fenómenos observable...

Figure 5. Example of the survey of the co-evaluation. Item: Conclusion of the students' work. $\bullet$ Absence of conclusions or inconsistent $\bullet$ Lack of rigor or has nothing to do with the objectives $\bullet$ Related to the objectives of the work, but the arguments are simple • The relationship with the objectives is clear. The arguments are solid. Relates to observable phenomena...

\title{
3 RESULTS
}

The success of the actions has been levelled mainly through a survey where 13 students of TML (36\%) and 18 students of MBS $(95 \%)$ answered.

\subsection{Theoretical classes}

The students in general considered very useful the document with the links to the videos recorded during the theoretical classes. The graph in Figure 6 shows that most of the students who consulted the documents found them very useful, a small part of the students never used them, and a minority did not consider them necessary. The graph contains the answers of the students of the two subjects.

\section{Documents with the links to the videos}

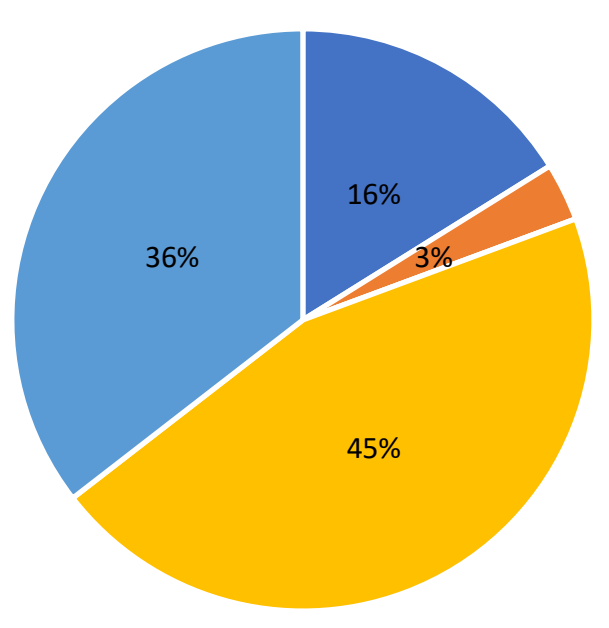

\author{
- I never consult them \\ - I consider them unnecessary \\ - I use them but can be \\ improved \\ - I have used them from time \\ to time. I consider them \\ useful and well organized \\ - I have used them frequently. I \\ consider them useful and \\ well organized
}

Figure 6. Survey about the documents with the links to videos

The Table 2 shows the total number of visits to the videos in both subjects. The ratio of visits calculated as the total number of visits per number of students and videos is similar in both subjects and it reveals that, on average, each student visits $20 \%$ of the videos. Taking into account that $16 \%$ of students recognized not to use the links the ratio, actually, should be higher. 
Table 2. Number of visits to the videos of theoretical sessions.

\begin{tabular}{l|c|c|c|c}
\hline \hline Subject & $\begin{array}{c}\text { Number of } \\
\text { students }\end{array}$ & $\begin{array}{c}\text { Number of } \\
\text { videos }\end{array}$ & $\begin{array}{c}\text { Number of } \\
\text { visits }\end{array}$ & Ratio \\
\hline TML & 36 & 32 & 235 & 0.2 \\
\hline MBS & 19 & 19 & 57 & 0.16 \\
\hline \hline
\end{tabular}

Figure 7 shows the distribution of the visits over the year. The arrows indicate the date of the exams. The distribution of the visits is quite homogeneous throughout the course, so it can be understood that the students used the videos to understand the subject during the course instead of to prepare the exams.

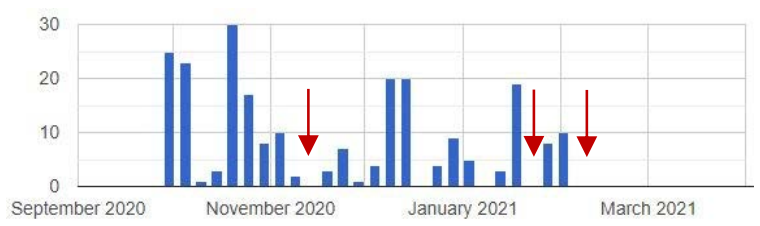

(a)

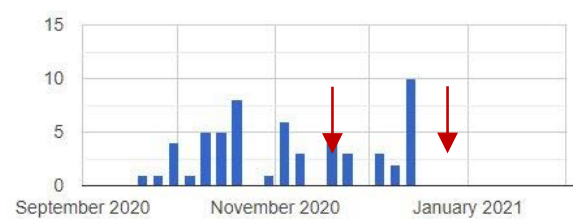

(b)

Figure 7. Visits to videos per date: (a) Subject TML; (b) Subject MBS

\subsection{Lab sessions}

The graph on Figure 6 shows the considerations of the students, about the links inserted in the lab booklets. In this case there is also a part of the students that does not used the videos, but those students that watched them considered explanatory and very useful. The difference between the two subjects could be due to the fact that the students of the subject MBS could choose between face to face and online sessions. Most of them preferred to attend face to face rather than the online format. So, in case of having doubts related to the use of the software, they could solve them by consulting directly with the teacher or their classmates instead of watching the videos.

\section{Links inserted in lab booklets}

MBS

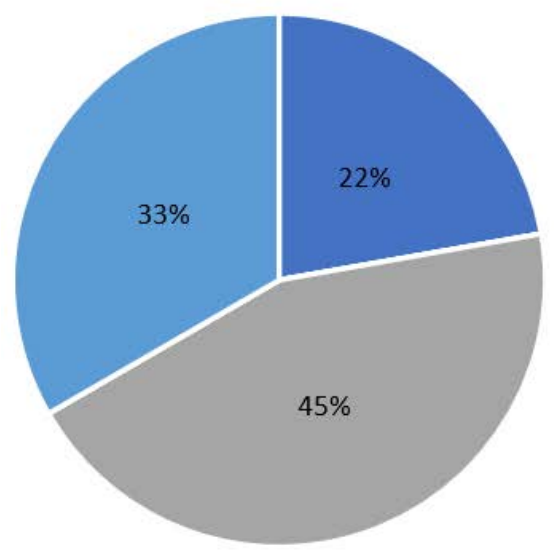

TML

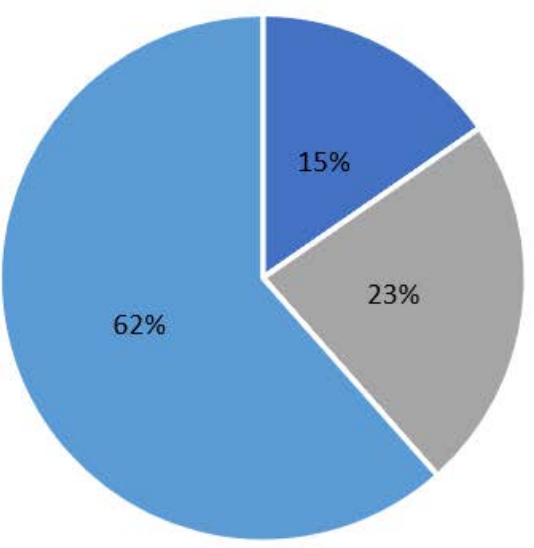

- I never use them

- I have used them from time to time. I consider them unnecessary

- I have used them from time to time. I consider them explanatory

=I have used them frequently, but they haven't helped me

- I have used them frequently. I consider them very useful

Figure 6. Survey about the links in the lab booklets

The number of visits to these videos is nor representative since they are shared by several subjects.

\subsection{Students' work}

The nineteen students of the subject Materials Behaviour in Service were grouped into twelve groups to do the works. The works were defended the last session of the course. For not depending on the 
confinements (or disease) caused by the COVID pandemic, it was strongly recommended to prepare a video instead of doing a live presentation.

Most of the groups showed reluctance to record the video since they did not have any previous experience. After providing the students some instructions, ten of the twelve groups followed the recommendations and only two groups presented their works live by Teams ${ }^{\circledR}$. Most of the videos had a very high quality. Most of the students properly participated in the co-evaluation except for two of them which had to make their presentation live.

\section{CONCLUSIONS}

The sudden outbreak of the global pandemic by COVID-19 forced an immediate adaptation of the traditional face-to-face educational model to an on-line model mediated by technology to the end of the 2019-2020 academic year. This situation highlighted the shortcomings of the university community in the use of ICT tools, from the lack of means of the institution to the dexterity in the management of technology applied to the teaching / learning process. Faced with this situation, the UPV promoted a series of initiatives to improve said deficiencies and in this context launched a call for PIME projects [7] in which, one of the thematic areas is the use of ICT. This work emerges from one of these projects.

During the 2020-2021 academic year, higher education institutions use BL models. The different BL models have been implemented by individual teachers given the new situation to which the learning mode had to be adapted. Therefore, the objective of this work is to analyse those initiatives that have worked best to obtain the best learning results for students, as well as those most useful ICT tools, since many of the ICT tools imposed by the pandemic will be installed in the daily professional development.

For both analysed subjects, several evidences of learning have been collected based on a well-defined system of rubrics and indicators, which are known in advance by students. Both the use of the ICT tools and the rubrics abovementioned allow to enhance the academic achievement of students regarding previous years. Furthermore, it allows students to acquire the transversal competences related to the analysis and problem solving and improves the ability to understand concepts intuitively. In addition, results clearly show a positive influence on the use of ICT tools for boosting the professional and ethical commitment to the issues raised.

\subsection{Theoretical classes}

Predictably, some of the students or the teacher, have followed the classes online during the term. In all cases, the developed materials and the followed methodology are considered valid for use in face-toface, online, and blended learning, thus providing the required flexibility. The level of success of having the recording of the sessions available was measured, mainly through a survey answered by the students, where $36 \%$ answered that they had consulted them frequently and $45 \%$ that they had consulted them from time to time. Furthermore, $91 \%$ of the students considered that the material was well organized.

In addition, objective data has been analyzed, such as the ratings and the number of visits or downloads of the documents uploaded to the UPV's e-learning platform. The videos have a reasonable number of visits since the students mainly used to follow live classes, in both cases face-to-face and online. The visits used to be distributed evenly over the course, which reinforces the idea that most of the students reviewed them to better understand the subject during the course.

Finally, it is concluded that broadcasting the theorical classes and letting the material to be consulted by the students would be very useful for blended learning or for face-to-face in the post-COVID era.

\subsection{Lab sessions}

The main contribution of ICT to lab sessions has occurred in computer lab sessions. The links and multimedia inserted in lab booklets have improved the self-learning process of the students. The survey shows that a $45 \%$ of the students had consulted them frequently and they considered them very useful and that a $36 \%$ had consulted them from time to time and considered them explanatory. However, they are not only useful for the students, but also for the teacher. We consider that in face-to-face or even in blended learning, the teacher could not have enough time to answer all the question from the student regarding the development of the lab sessions, so these links and multimedia could answer them these questions, favoring the student's self-learning. 
Referring to the laboratories, face-to-face implementation continues to be irreplaceable. Undoubtedly, the developed materials can facilitate the deliveries of the students, but the experimental part must continue to be face-to-face. Given the exceptional circumstances of the health situation, the ICTs have made possible to hold a laboratory session, but it is not considered that it has reached the same learning level as in a traditional session.

\subsection{Students' work}

The implementation of ICTs by students in the defense of their works has been highly satisfactory. Despite the lack of experience, most of them recorded a video to do the presentation of their work instead of doing live presentations. The quality of the videos was very high.

During the session dedicated to the presentation of the works, the students could be aware during the presentation of their colleagues, which allowed a high participation in the co-evaluation. This aspect could be interesting even in the post-COVID era.

\section{ACKNOWLEDGEMENTS}

Authors gratefully acknowledge the financial support of the Vicerrectorado de Estudios, Calidad y Acreditación and the Vicerrectorado de Recursos Digitales y Documentación of the Universitat Politècnica de València (project PIME B/19-20/165 and project PIME C/20-21/201) and the Instituto de Ciencias de la Educación of the Universitat Politècnica de València (EICE INTEGRAL).

\section{REFERENCES}

[1] B. Ross and K. Gage, "Global perspectives on blended learning: Insight from WebCT and our customers in higher education" in The handbook of blended learning: Global perspectives, local designs (C.J. Bonk and C.R. Graham eds.), 155-168, San Francisco (CA): Pfeiffer Publishing, 2006.

[2] A. Norberg, C.D. Dziuban and P.D. Moskal, "A time-based blended learning model", On the Horizon, vol. 19, no. 3, 207-216, 2011. (Doi:10.1108/10748121111163913)

[3] C.R. Graham, "Emerging practice and research in blended learning" in Handbook of distance education (3rd ed.) (M.J. Moore eds.), 333-350, New York (NY): Routledge, 2013.

[4] C.R. Graham, W. Woodfield and J.B. Harrison, "A framework for institutional adoption and implementation of blended learning in higher education" The Internet and Higher Education, vol. 18, 4-14, 2012.

[5] W.W. Porter, C.R. Graham, K.A. Spring and K.R. Welch, "Blended learning in higher education: Institutional adoption and implementation" Computers \& Education, vol. 75, 185-195, 2014.

[6] Microsoft Teams, Accessed 11 May, 2021. Retrieved from https://www.microsoft.com/en$\mathrm{gb} /$ microsoft-teams/group-chat-software

[7] Convocatoria Aprendizaje + Docencia 2020, Accessed 11 May, 2021. Retrieved from https://www.upv.es/contenidos/ICEP/info/760700normalc.html 